\title{
Implementation of a Home-based Exercise Program for Cardiopulmonary Rehabilitation Patients during the SARS-CoV-2 Pandemic
}

\author{
Gabriel Espinosa, ${ }^{1,2}$ Leandro Toledo, ${ }^{1}$ Christiane Prado, ${ }^{1}$ Gabriel Otávio de Moura Moraes, ${ }^{1 \oplus}$ Fernanda Domecg, ${ }^{1}$ \\ Marcelo Riccio Facio, ${ }^{1}$ Fabricio Braga da Silva ${ }^{1,3}$
}

Laboratório de Performance Humana, ${ }^{\prime}$ Rio de Janeiro, RJ - Brazil

Universidade Federal Fluminense, ${ }^{2}$ Niterói, RJ - Brazil

Casa de Saúde São José, ${ }^{3}$ Rio de Janeiro, RJ - Brazil

\section{Abstract}

Background: In pandemic times, social isolation is of utmost importance to minimize the spread of the SARS-Cov-2 virus. At times like these, home fitness becomes extremely necessary to avoid sedentarism and decompensation in chronic disease patients.

Objectives: Evaluate the engagement of rehabilitation patients to a tele- oriented exercise program at home (TOEP).

Materials and Methods: 66 of 94 patients (63.8\% males; $65.5 \pm 14$ years old; $5.2 \pm 2.6$ months in rehabilitation) agreed to take part. Subjects were grouped in three levels of functionality to guide the exercise prescription. Weekly Training Rates (WTR) were compared using the Friedman test and corrected by Dunn's test. A multivariate logistic model was designed to determine independent predictors in program engagement. Statistical significance was determined by a $\mathrm{p}<0.05$.

Results: TOEP provided WTR similar to the pre-quarantine values of 2.8/week ( $>0.05)$, and $91.8 \%$ of patients took part until the end of those 5 weeks. The presence of diabetes was a predicted factor for low engagement to TOEP with relative risk of 0.41 (CI95\%: 0.25 to 0.66 ).

Conclusion: TOEP provided satisfactory engagement in rehabilitation patients. Most of them increased WTR during quarantine. Patients with diabetes displayed lower engagement to the minimum standard frequency.

Keywords: Home Officer; Rehabilitation-Orientation/telemedicine; Rehabilitation Cardiac; Health Services/telemedicine.

\section{Introduction}

Ever since infectious disease transmission mechanisms became known, social isolation has been a strategy to control most epidemics. ${ }^{1}$ This strategy has been adopted against 2019 SARS-COV2 pandemic in most countries worldwide, with varied rigorousness depending on the region. What seems to be unanimous is the directive for total social isolation for the elderly and chronicle disease patients. The reasons behind this recommendation are the ever-so-great number of recent publications pointing out the unfavorable evolution of COVID-19 among this population. $\mathrm{Wu}$ and McGoogan analyzed more than seventy thousand cases of COVID-19, reporting that the mortality rate by COVID-19 was $10.5 \%$ for cardiovascular disease patients and $6 \%$ for hypertensive patients. ${ }^{2}$ These rates were higher than the $2.3 \%$ rate noticed in the same sample by the general population. In the same publication, death rate was 8 and $14.8 \%$ for individuals between 70 and 79 years old and over 80 years old, respectively. Patients with cancer presented an even higher risk of morbimortality. ${ }^{3}$

Home-based rehabilitation strategies with or without remote monitoring have already been classified as an urgent matter with regard to patients' engagement in rehabilitation programs. ${ }^{4}$ Telemedicine strategies have 
been used with this purpose. ${ }^{5} \mathrm{~A}$ meta-analysis including 11 studies concludes that it is at least as effective as a center-based rehabilitation in improving modified risk factors and aerobic capacity. ${ }^{6}$

In pandemic times, keeping chronic disease patients at home with their compensated illnesses is an extremely important clinical and epidemiological measure. Physical exercise becomes imperative in this process. Given the circumstances, remote-based guiding and surveillance strategies supported by technological resources are the only possible tools. ${ }^{9}$ This study aims at evaluating the engagement of center-based rehabilitation patients in a tele- oriented exercise program at home (TOEP).

\section{Materials and Methods}

\section{Sample}

On March $18^{\text {th }}$, immediately after Health authorities declared social isolation as a sanitary measure to control the pandemic, our rehabilitation center suspended its face-to-face activities. All patients taking part in different kinds of rehabilitation programs were invited to join the Exercise Centre. A total of 94 patients were invited (63.8\% men, mean age: 69.0 [58.7; 75.0] years old, and median time at rehabilitation: 5.3 [2.9; 7.4] months). Patients displayed different comorbidities, such as cardiovascular disease, lung disease, cancer, and diabetes. Some of those patients were fragile elderly with sarcopenia or other muscle-skeleton conditions and prehabilitation.

The sudden closing of all establishments made it necessary a fast implementation of a strategy that would enable patients to keep up with the rehabilitation regimen. The proposal should be effective in providing physical activities and either improve or, at best, maintaining patients' physical aptitude. It was also necessary to be easily accessible, so that patients could immediately perform their activities at home, using minimum resources, in a safe way, to ensure no harm to the physical integrity, as well as to respect their level of autonomy and the previously evaluated physiopathological limitations. Lastly, it was of utmost importance that the strategy was sustainable, due to an undetermined staff reduction and limited working hours, while preserving their safety.

\section{Exercise prescription}

To make the program viable to all patients, the exercise team elaborated different plans for all three levels of functionality, considering falling risks, degree of autonomy, and patient-training experience (Figure 1). Once the plans were elaborated, to better adapt to the exercises, patients were analyzed one by one and then classified in accordance with plans A, B, and C. Some patients who required specific attention beyond the three plans were allocated in a special plan (SP). Based on the Rockwood et al. ${ }^{10}$ protocol, patients' individual frailty level was verified after group distribution.

Exercises were prescribed using body weight, whole body, or most of the muscle groups. Isolated upperbody exercises were not prescribed due to the difficulty of performing them without additional equipment. The number of exercises, the execution (stable positioning), the use of support and the speed to execute were differentiating issues between plans.

Training load progression was based on volume increase during the weeks, being adjusted by changing the number of repetitions, bout duration and number of series in each session or adjusting recovering interval between series in each suggested band (Figure 1). Demonstrative videos were recorded to help patients understand each exercise. Each exercise plan was designed to last 30 to $45 \mathrm{~min}$. Patients with access to ergometers or open spaces would be instructed to choose a free complementary aerobic exercise such as a 10-30-minute additional walk. To maintain low intensity, we used as reference anaerobic Heart rate predetermined in a cardiopulmonary exercise test or effort subjective perception $<5$ in a $0-10$ scale.

\section{Surveillance}

Patients were distributed among team professionals, considering one professional assigned to each patient as a reference to contact during social isolation. This professional was in charge of communicating daily with their patients, introduce the program, address doubts, and make themselves available for remote supervision, whenever necessary. A flow of communication was established, where each professional should send their patients a standardized initial message, introducing themselves. Once participation in the program was confirmed, exercise plans A, B, C, or SP were sent with specifications according to each case, as well as explanatory exercise videos. These professionals were responsible for keeping in touch with patients, three times a week, through text messages or email, with a conference call every fifteen days. Weekly reports were 


\begin{tabular}{|c|c|c|c|}
\hline & PLAN A & PLAN B & PLAN C \\
\hline $\begin{array}{l}\text { Functional } \\
\text { class }\end{array}$ & $\begin{array}{l}\text { Frail patients with a higher } \\
\text { risk of fall or special clinical } \\
\text { limitation. }\end{array}$ & $\begin{array}{l}\text { patients with a low risk of fall } \\
\text { and few exercise experience } \\
\text { or reduced exercise } \\
\text { capacity. }\end{array}$ & $\begin{array}{l}\text { Patinets with advanced } \\
\text { fitness for reabilitation. }\end{array}$ \\
\hline Exercises & $\begin{array}{l}\text { A1. Stationary walk (s) } \\
\text { A2. Single leg chair Knee } \\
\text { extension (R) } \\
\text { A3. Isometric pelvic Bridge } \\
\text { (s) } \\
\text { A4. Hip abduction (R) } \\
\text { A5. Front Planck with } \\
\text { straight elbow and hands on } \\
\text { a bed (s) } \\
\text { A6. Calf rise (R) } \\
\text { A7. Hip adduction (sited on a } \\
\text { chair) (s) }\end{array}$ & $\begin{array}{l}\text { B1. Stationary walk (s) } \\
\text { B2. Chair Sit and rise }(R) \\
\text { B3. Dynamic pelvic bridge (R) } \\
\text { B4. Hip abduction (R) } \\
\text { B5. Front plank with } \\
\text { straight elbow and hands on } \\
\text { a bed (s) } \\
\text { B6. Calf rise (R) } \\
\text { B7. Hip adduction (sited on a } \\
\text { chair) (s) } \\
\text { B8. Stationary walk (s) }\end{array}$ & $\begin{array}{l}\text { C1. Stationary Run (s) } \\
\text { C2. Chair Sit and rise (R) } \\
\text { C3. Lunge (R) } \\
\text { C4. Single leg Isometric } \\
\text { pelvic Bridge (s) } \\
\text { C5. Stationary Run (s) } \\
\text { C6. Hip adduction (sat on a } \\
\text { chair) (s) } \\
\text { C7. Hip adduction (sat on a } \\
\text { chair) (s) } \\
\text { C8. Front planck (s) } \\
\text { C9. Calf rise (R) } \\
\text { C10. Bird-dog (s) } \\
\text { C11. Stationary Run (s) }\end{array}$ \\
\hline $\begin{array}{l}\text { Volume } \\
\text { range }\end{array}$ & $\begin{array}{l}\text { Sets: } 2 \text { to } 3 \\
\text { Duration: } 6 \text { to } 12(R) \text { or } 15 \text { to } \\
30(s) \\
\text { Rest: } 20 \text { to } 60(s) \\
\text { Frequency: } 3 \text { to } 5 \text { days/ } \\
\text { week }\end{array}$ & $\begin{array}{l}\text { Sets: } 2 \text { to } 3 \\
\text { Duration: } 8 \text { to } 20(R) \text { or } 20 \text { to } \\
40 \text { (s) } \\
\text { Rest: } 20 \text { to } 60(s) \\
\text { Frequency: } 3 \text { to } 5 \text { days/ } \\
\text { week }\end{array}$ & $\begin{array}{l}\text { Sets: } 2 \text { to } 4 \\
\text { Duration: } 8 \text { to } 20(R) \text { or } 20 \text { to } \\
60(\mathrm{~s}) \\
\text { Rest: } 20 \text { to } 60 \text { (s) } \\
\text { Frequency: } 3 \text { to } 5 \text { days/ } \\
\text { week }\end{array}$ \\
\hline
\end{tabular}

Figure 1 - Exercise plans general scope.

Source: the author (2020). Exercises with volume based on duration in seconds (s) and on the number of repetitions (R). Unilateral (UL)

added to the database system, stating the number of exercise sessions done in the past week, as well as a brief well-being and symptom evaluation. Since most patients were in the COVID-19 risk group, in case any of them displayed COVID-19 symptoms, exercising would be immediately suspended, and an assistant doctor would be notified.

\section{Complementary assistance}

In addition to three doctors and two physical educators in the staff for exercise prescription and control, the program also involved two nutritionists and a psychologist for further complementary assistance. These professionals were able to offer regular online support to patients. Besides physical training, healthy eating behavior and stress control are of utmost importance in these times. Therefore, patients were offered additionally a "healthy entertainment" program, with live videos, where the team of professionals tackled topics regarding food storage and re-use, as well as eating behavior during isolation, exercise recommendation classes, and meditation and mindfulness workshops, aiming at helping to control anxiety.

\section{Statistical analysis}

The data distribution was tested using the Kolmogorov-Smirnov test. Continuous variables related to the characteristics of the population were expressed in median and interquartile interval and compared through U-Mann-Whitney test. Age comparison and frailty between training plans was made using the Kruskal-Wallis test. The categorical variables were expressed in percentage and compared through chi-square test or Fisher exact. The variations in weekly training rate (WTR) pre-quarantine and along the five-week TOEP were compared using the Friedman test. Pairwise comparison post-hoc between weeks was made by Dunn's test. Variations in attendance were tested considering a WTR $\geq 3$ per week throughout the weeks and compared by the McNemar test. 
It was considered satisfactory engagement WTR $\geq 3$ per week in at least 4 out 5 weeks of training. A multivariate logistic regression model was created to determine independent engagement predictors containing age and variables with an error probability alfa $\leq 10 \%$ in the univariate analysis (chi-square and Mann-Whitney U). The statistical significance was defined by an alfa $<5 \%$ probability error. The statistical analysis was conducted using a SPSS program (SPSS 22.0 for Windows, IBM SPSS, IL, US). This research was approved by the Hospital Federal Cardoso Fontes ethical and research committee under the protocol 36149020.6.0000.8066 and 4.258.930. All the procedures are in accordance with the Helsinki declaration 1975, updated in 2013.

\section{Results}

Table 1 presents the characteristics of the sample and engagement rate by gender and clinical conditioning. By comparing individuals who participated or not, there was no difference in age, gender-prevailing illnesses and training characteristics. Frailty was the only different variable, with participants frailer than the non-participants.
The distinction between patients in exercise plans A, B, and $\mathrm{C}$ enabled effective distinction according to age and patient functionality (Table 2). Individuals classified as plan $\mathrm{C}$ were significantly younger than the others. With regard to frailty, group distribution provided the expected distinction, confirmed by the analysis of the Rockwood scale ${ }^{10}$, so there was no overlapping in the group distribution.

TOEP had $91.8 \%$ engagement among participant patients. With respect to WTR, in the face-to-face physical training program previously adopted by patients, the average was of $2.7 \pm 0.1$ sessions per week (Figure 2). Since the implementation of home-based exercise program, the same previous average of $2.8 \pm 0.2$ sessions of weekly training were kept. It was possible to notice no evolution each week. In the beginning, there was a reduction in WTR followed by a rise in the second week, for values higher than the previous average, which was sustained until the end.

WTR $\geq 3$ trains per week was observed in 27.9; 77.0; $60.7 ; 67.2$ and $72.1 \%$ of participants in weeks 1 and 5, respectively. Variations were significant between weeks 1 and $2(p<0.001)$ and weeks 2 and $3(p=0.007)$.

Table 1 - Sample characteristics

\begin{tabular}{|c|c|c|c|c|}
\hline & Total & Non-Participant & Participant & $p$ value \\
\hline Patients (n) & 94 & 33 & 61 & \\
\hline Male (\%) & $62.8 \%$ & $60.6 \%$ & $63.9 \%$ & $0.75^{\&}$ \\
\hline Age (years) & $69.0(58.7 ; 75.0)$ & $70.0(61.5 ; 77.0)$ & $67.0(51.5 ; 75.0)$ & $0.17^{*}$ \\
\hline Hypertension (\%) & $59.6 \%$ & $72.7 \%$ & $52.5 \%$ & $0.056^{8 x}$ \\
\hline $\mathrm{DM}(\%)$ & $27.7 \%$ & $30.3 \%$ & $26.2 \%$ & $0.673^{\&}$ \\
\hline AMI (\%) & $20.2 \%$ & $18.2 \%$ & $21.3 \%$ & $0.718^{\#}$ \\
\hline Heart failure (\%) & $9.6 \%$ & $6.1 \%$ & $11.5 \%$ & $0.486^{\#}$ \\
\hline Angioplasty (\%) & $33.0 \%$ & $39.4 \%$ & $29.5 \%$ & $0.331^{\&}$ \\
\hline CABG $(\%)$ & $11.7 \%$ & $6.1 \%$ & $14.8 \%$ & $0.318^{\sharp}$ \\
\hline COPD $(\%)$ & $13.8 \%$ & $15.2 \%$ & $13.1 \%$ & $0.785^{\sharp}$ \\
\hline ILD (\%) & $4.3 \%$ & $6.1 \%$ & $3.3 \%$ & $0.524^{\#}$ \\
\hline Cancer (\%) & $22.3 \%$ & $33.3 \%$ & $16.4 \%$ & $0.06^{\&}$ \\
\hline Frailty & $8.0(7.0 ; 8.0)$ & $7.0(6.5 ; 8.0)$ & $8.0(7.0 ; 9.0)$ & $0.004^{*}$ \\
\hline WTR & $3.0(2.0 ; 3.0)$ & $2.0(2.0 ; 3.0)$ & $3.0(2.0 ; 3.0)$ & $0.065^{*}$ \\
\hline Rehabilitation time (months) & $5.3(2.9 ; 7.4)$ & $5.1(2.8 ; 7.4)$ & $5.3(3.0 ; 7.5)$ & $0.924^{*}$ \\
\hline
\end{tabular}


Table 2 - Age and frailty comparison among exercise groups

\begin{tabular}{lccccc} 
& Plan & Plan & Plan & Special \\
& A & B & C & p & $<0.001$ \\
Age & $74(71 ; 78)$ & $74(68 ; 78)$ & $54(46 ; 63)$ & $64(52 ; 66)$ & $<0.001$ \\
Frailty & $6(6 ; 6)$ & $8(7 ; 8)$ & $9(8 ; 9)$ & $8(7 ; 8)$ & \\
\hline
\end{tabular}

Source: the author (2020). Median values (interquartile amplitude). Significance determined by the Kruskal-Wallis test.

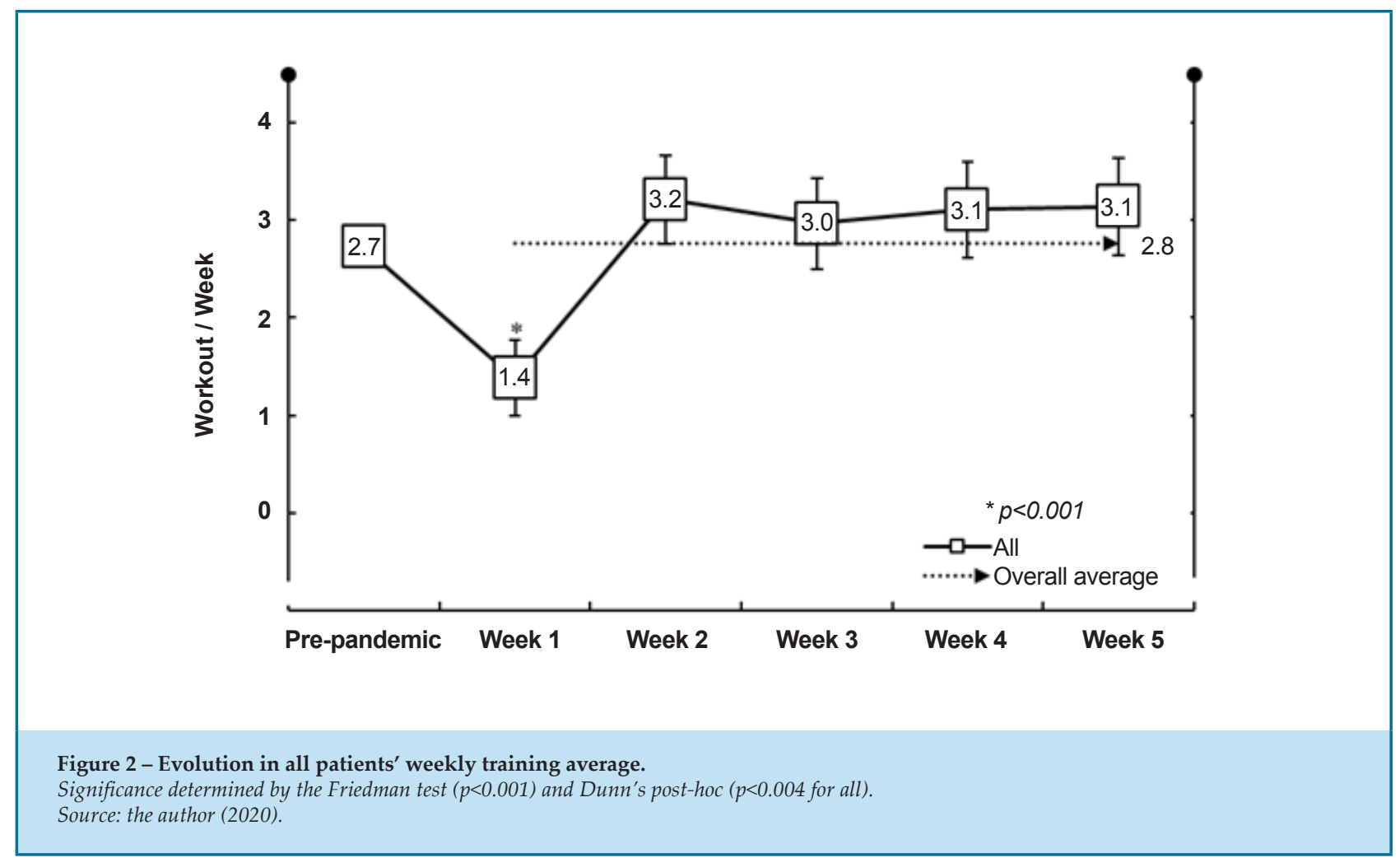

While comparing the fifth week with the previous training period (pre-quarantine) $29.5 \%$ of patients reduced $13.1 \%$ kept and $57.4 \%$ had a significant increase in WTR.

Multivariate analysis is show on Table 3. DM was the only independent predictor of engagement equal or higher than three training sessions per week within at least 4 weeks in the program. Figure 3 illustrates the evolution of WTR in stratified patients through the presence/absence of DM.

\section{Discussion}

In this study, after moderated engagement in the remote rehabilitation program (63.9\%), participants' involvement was considered good. By the end of the fifth week, 91.8\% kept in touch with the program. Several rehabilitation centers interrupted their face-to-face activities during the pandemic and invited their patients to join remote rehabilitation programs, ${ }^{11,12}$ but in the light of the authors' knowledge, this is the first publication that describes patient engagement and commitment to the home-based tele-oriented exercise program.

The highest multicentric register so far (1,653 patients with heart failure) reported an engagement of $85.6 \%$ right at the beginning of the program. ${ }^{13}$ At the end of the 24 weeks, only 55\% of the patients kept in touch with the telemonitoring system. Stampehl et al. ${ }^{14}$ presented that at the end of 31 days, there were $66.7 \%$ of participant patients 
Table 3 - Predictors of more than 4 weeks with minimum 3 training sessions/week

\begin{tabular}{|c|c|c|c|c|}
\hline & Present & Absent & $\begin{array}{l}\text { Univariate } \\
\text { RR (IC95\%) }\end{array}$ & $\begin{array}{c}\text { Multivariate } \\
\text { RR (IC95\%) }\end{array}$ \\
\hline Male & $53,8 \%$ & $54,5 \%$ & $0,99(0,61 ; 1,60)$ & \\
\hline Age $\leq 65$ y/o & $55.2 \%$ & $53.1 \%$ & $0.95(0.55 ; 1.65)$ & \\
\hline SAH & $53.1 \%$ & $55.2 \%$ & $0.95(0.55 ; 1.65)$ & \\
\hline $\mathrm{DM}$ & $18.8 \%$ & $66.7 \%$ & $0.41(0.25 ; 0.66)$ & $0.097(0.02 ; 0.44)$ \\
\hline AMI & $69.2 \%$ & $50.0 \%$ & $1.62(0.69 ; 3.85)$ & \\
\hline $\mathrm{CHF}$ & $71.4 \%$ & $51.9 \%$ & $1.68(0.50 ; 5.60)$ & \\
\hline Angioplasty & $61.1 \%$ & $51.2 \%$ & $1.25(90.62 ; 2.41)$ & \\
\hline MRS & $66.7 \%$ & $51.9 \%$ & $1.44(0.55 ; 3.80)$ & \\
\hline COPD & $62.5 \%$ & $52.8 \%$ & $1.25(0.49 ; 3.20)$ & \\
\hline ILD & $50.0 \%$ & $54.2 \%$ & $0.91(0.22 ; 3.76)$ & \\
\hline Cancer & $50.0 \%$ & $54.9 \%$ & $0.90(0.45 ; 1.80)$ & \\
\hline Frailty & $50.0 \%$ & $54.9 \%$ & $0.90(0.45 ; 1.80)$ & \\
\hline Rehabilitation time $<3$ months & $50.0 \%$ & $55.8 \%$ & $0.90(0.52 ; 1.52)$ & \\
\hline
\end{tabular}

Source: the author (2020). SAH: Systemic Arterial Hypertension; DM: Diabetes Mellitus; AMI: Acute Myocardial Infarction; CHF: Congestive Heart Failure; MRS: Myocardial Revascularization Surgery; COPD: Chronic Obstructive Pulmonary Disease; ILD: Interstitial Lung Disease.

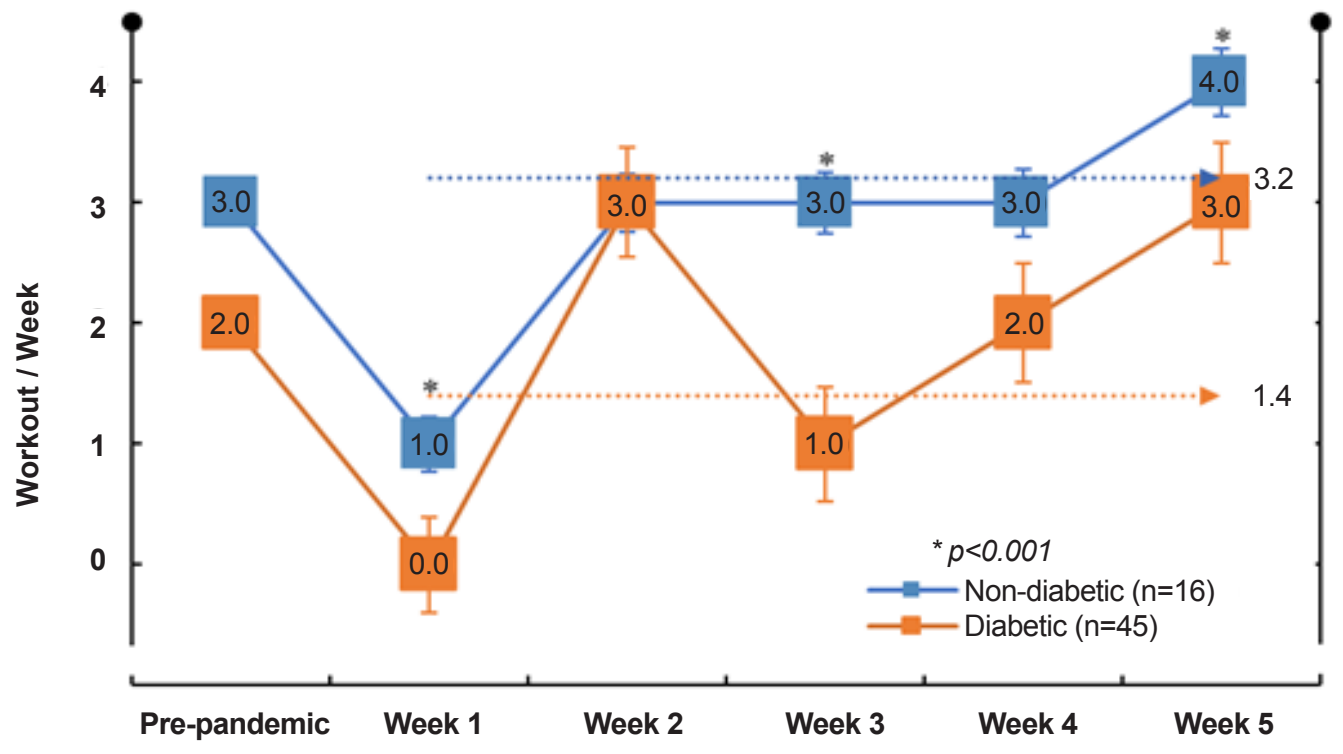

Figure 3 - Weekly training rate in patients stratified by absence/presence of diabetes. Significance referred to Mann-Whitney U test. Source: the author (2020). 
engaged in the program. Unfortunately, the DIAL study, ${ }^{15}$ which included 1,518 patients with heart failure, excluded physical exercise from its engagement criterion.

Although engagement criteria and monitoring plan may vary across studies, in both cases a larger rate of engagement has been related to a lower number of events in this population.

Beyond the satisfactory engagement rate, the main finding in this study is the efficiency in keeping patients exercising. A 2.9 days per week WTR average was observed, with more than $70 \%$ of patients exercising more than 3 days a week after 5 weeks of quarantine, which can be considered a good result. Besides, more than half of the patients exercised 3 or more days/ week in 4 out of 5 weeks, and $57.4 \%$ were exercising more than they did before isolation. Some studies have already evaluated the rate of exercising during telemonitored home-based rehabilitation sessions. Kraal et al. ${ }^{16}$ and Laustsen et al. ${ }^{17}$ after 12 weeks of training, reported WTR $2 \pm 0.6$ and 2.6 \pm 0.5 days/weeks, respectively. Another group has published a similar result of WTR 2.5 \pm 0.3 days/weeks within 12 weeks using a cell phone based exercise plan. ${ }^{18}$

The presence of diabetes was the only independent predictor of exercise engagement within the analyzed period. Only $18.8 \%$ of the patients with diabetes were able to exercise 3 times a week in 4 out of 5 weeks. The low engagement to exercise programs by patients with diabetes in different countries has been known for years, ${ }^{19,20}$ and their rate vary around $60 \%$ of inactivity after adjustments. Reasons for that include difficulty to engage and fatigue, among others. ${ }^{21}$ Many studies have used telemedicine exercise plans to boost physical activity engagement in patients with diabetes, ${ }^{22,23}$ successfully. Duruturk and Özköslü ${ }^{24}$ performed a random study including 44 patients with diabetes where participants were offered a 6-week home-based exercise program (an average of 2.66 sessions per week), with the support of a physiotherapist by video-conference. Participants not only showed significant improvement in fitness, but also improved glycemic control and reduced symptoms of depression.

Diabetes is a risk factor for COVID-19 mortality. ${ }^{2}$ Thus, we believe that isolation may be recommended for a longer period for this population, ${ }^{25}$ even after flexibilization may reach the general population. On the other hand, sedentarism and low physical exercise engagement are risk factors for the development of macro and microvascular events in patients with diabetes. ${ }^{26}$
The difficulty for full individualization of TOEP exercise prescriptions may be a limiting factor for its efficacy. However, TOEP was a fast-solution plan in order to keep patients engaged in physical activities, while allowing them to manage their clinical conditions. To evaluate patients' points of view regarding the program would help understand its efficacy. This type of analysis demands the use of mixed methods of investigation. Considering the urgency of the program, there was no available time to develop an evaluation tool that could reflect perception and individual satisfaction.

Moreover, to ensure efficacy, it would have been necessary that patients go through a pre- and postintervention for cardiopulmonary performance. In these regards, the exercise plan has data of previous evaluations for each patient and will soon be reevaluated. WTR is the main measure of attendance and was based on patients' personal feedback. Pre-pandemic frequency was based on the program in which patients were enrolled, and not in attendance.

\section{Conclusion}

In this small sample, the development of a fasttracking remote rehabilitation program, comprised by center-based rehabilitation concepts and data, was well-received by the participants. The exercise plans were adequate, and patients were able to maintain good exercise rates after 5 weeks of quarantine. Patients with diabetes showed lower engagement and deserve special attention in future exercise plans. In pandemic times, developing efficient and safe tele-rehabilitation plans must be regarded as a scientific urgent matter.

\section{Author contributions}

Conception and design of the research: all authors. Acquisition of data: Espinosa G, Toledo L, Prado C, Moraes G, DOmecg F, Facio M. Analysis and interpretation of the data: Espinosa G, Braga F. Statistical analysis: Braga F. Writing of the manuscript: Espinosa G, Toledo L, Prado C, Moraes G, DOmecg F, Facio M. Critical revision of the manuscript for intellectual content: Espinosa G, Braga F.

\section{Potential Conflict of Interest}

No potential conflict of interest relevant to this article was reported. 


\section{Sources of Funding}

There were no external funding sources for this study.

\section{Study Association}

This study is not associated with any thesis or dissertation work.

\section{References}

1. Yu D, Lin Q, Chiu AP, He D. Effects of reactive social distancing on the 1918 influenza pandemic. PLoS One. 2017;12(7):e0180545.

2. Wu Z, McGoogan JM. Characteristics of and important lessons from the coronavirus disease 2019 (COVID-19) outbreak in China: Summary of a Report of 72314 Cases from the Chinese Center for Disease Control and Prevention. JAMA. 2020;323(13):1239-42.

3. Zhang L, Zhu F, Xie L, Wang C, Chen R, Jia P, et al. Clinical characteristics of COVID-19-infected cancer patients: a retrospective case study in three hospitals within Wuhan, China. Ann Oncol. 2020;31(7):894-901.

4. Thomas RJ, Beatty AL, Beckie TM, Brewer LC, Brown TM, Forman DE, et al. Home-based cardiac rehabilitation: a scientific statement from the American Association of Cardiovascular and Pulmonary Rehabilitation, the American Heart Association, and the American College of Cardiology. Circulation. 2019;140(1):E69-89.

5. Gensini GF, Alderighi C, Rasoini R, Mazzanti M, Casolo G. Value of Telemonitoring and Telemedicine in Heart Failure Management. Card Fail Rev. 2017;3(2):1116-21.

6. Rawstorn JC, Gant N, Direito A, Beckmann C, Maddison R. Telehealth exercise-based cardiac rehabilitation: a systematic review and metaanalysis. Heart. 2016;102(15):1183-92.

7. Bai Y, Yao L, Wei T, Tian F, Jin DY, Chen L, et al. Presumed Asymptomatic Carrier Transmission of COVID-19. JAMA. 2020;323(14):1406-7.

8. Owen N, Sparling PB, Healy GN, Dunstan DW, Matthews CE. Sedentary behavior: emerging evidence for a new health risk. Mayo Clin Proc. 2010;85(12):1138-41.

9. Cristo D, Nascimento NP, Dias AS, Sachetti A. Telerehabilitation for cardiac patients: systematic review. Int J Cardiovasc Sci. 2018;31(4):443-50.

10. Rockwood K, Song X, MacKnight C, Bergman H, Hogan DB, McDowell I, et al. A global clinical measure of fitness and frailty in elderly people. CMAJ. 2005;173(5):489-95.

11. ACRA - Australian Cardiovascular Health and Rehabilitation Association. Webinar: COVID-19 and Cardiac Rehabilitation [citado 02 maio 2020]. Disponível em: https://www.acra.net.au/event/unpackingthe-a-pathway-to-cardiac-recovery-standardised-program-content-forphase-ii-cardiac-rehabilitation-2/.

12. Vigorito C, Faggiano P, Mureddu GF. COVID-19 pandemic: what consequences for cardiac rehabilitation? Monaldi Arch Chest Dis. 2020;90(1). [Epub ahead of print].

13. Chaudhry SI, Mattera JA, Curtis JP, Spertus JA, Herrin J, Lin Z, et al. Telemonitoring in patients with heart failure. N Engl J Med. 2010;363(24):2301-9.

\section{Ethics approval and consent to participate}

This study was approved by the Ethics Committee of the Hospital Federal Cardoso Fontes - HFCF under the protocol number 4.258.930. All the procedures in this study were in accordance with the 1975 Helsinki Declaration, updated in 2013. Informed consent was obtained from all participants included in the study.

14. Stampehl MR, Jennison SH, Call C, Venkatagiri BK, Parrot K, Norman $\mathrm{HS}$, et al. Adherence to a telehealth heart failure program was associated fewer hospitalizations. J Card Fail. 2017;23(8):S80.

15. Ferrante D, Varini S, MacChia A, Soifer S, Badra R, Nul D, et al. Longterm results after a telephone intervention in chronic heart failure: DIAL (Randomized trial of phone intervention in chronic heart failure) follow-up. J Am Coll Cardiol. 2010;56(5):372-8.

16. Kraal JJ, Peek N, Akker-Van Marle ME, Kemps HM. Effects of homebased training with telemonitoring guidance in low to moderate risk patients entering cardiac rehabilitation: short-term results of the FIT@ Home study. Eur J Prev Cardiol. 2014;21(2 suppl):26-31.

17. Laustsen S, Oestergaard LG, Tulder M, Hjortdal VE, Petersen AK Telemonitored exercise-based cardiac rehabilitation improves physical capacity and health-related quality of life. J Telemed Telecare 2020;26(1-2):36-44

18. Widmer RJ, Allison TG, Lerman LO, Lerman A. Digital health intervention as an adjunct to cardiac rehabilitation reduces cardiovascular risk factors and rehospitalizations. J Cardiovasc Transl Res. 2015;8(5):283-92.

19. Morrato EH, Hill JO, Wyatt HR, Ghushchyan V, Sullivan PW. Physica activity in U.S. adults with diabetes and at risk for developing diabetes, 2003. Diabetes Care. 2007;30(2):203-9.

20. Negera GZ, Epiphanio DC. Prevalence and predictors of nonadherence to diet and physical activity recommendations among type 2 diabetes patients in Southwest Ethiopia: a cross-sectional study. Int J Endocrinol. 2020 Feb 28;2020:1512376.

21. Thomas N, Alder E, Leese GP. Barriers to physical activity in patients with diabetes. Postgrad Med J. 2004;80(943):287-91

22. Mori DAL, Silberbogen AK, Collins AE, Ulloa EW, Brown KL, Niles BL. Promoting physical activity in individuals with diabetes: Telehealth approaches. Diabetes Spectrum. 2011;24(3):127-35

23. Klonoff DC. Using telemedicine to improve outcomes in diabetes an emerging technology. J Diabetes Sci Technol. 2009;3(4):624-8.

24. Duruturk N, Özköslü MA. Effect of tele-rehabilitation on glucose control, exercise capacity, physical fitness, muscle strength and psychosocial status in patients with type 2 diabetes: A double-blind randomized controlled trial. Prim Care Diabetes. 2019;13(6):542-8

25. Muniyappa R, Gubbi S. COVID-19 pandemic, corona viruses, and diabetes mellitus. Am J Physiol Endocrinol Metab. 2020;318(5):E736-41.

26. Brugnara L, Murillo S, Novials A, Rojo-Martínez G, Soriguer F, Goday A, et al. Low physical activity and its association with diabetes and other cardiovascular risk factors: a nationwide, population-based study. PLoS One. 2016;11(8):e0160959. 